\title{
Mentoring as a Predominant Factor Affecting Well-Being of Older People
}

\author{
Emiliya Pluchevskaya $^{\mathrm{a}}$, Elena Burmakova ${ }^{\mathrm{a}}$, Natalia Varlacheva ${ }^{\mathrm{a}}{ }^{\mathrm{a}}$ \\ * Corresponding author: Emiliya Pluchevskaya, emilyval@tpu.ru \\ ${ }^{a}$ National Research Tomsk Polytechnic University, Tomsk 634012 Russia, tpu@tpu.ru
}

\begin{abstract}
http://dx.doi.org/10.15405/epsbs.2016.02.10

The authors of the paper studied the state of well-being of older people who retired and stop working at the company they have worked for over 20 years. The survey provided some useful insights into the problem with the reference to three samples of 10 older people from each group: 1) older people who retired and keep in touch with the previous organisation; 2) older people who retired and continue working at the company as consultants, supervisors, experts, mentors etc.; 3) older people who retired and work in another enterprise and lost the touch with the previous organisation. Retired people took part in present research by completing a questionnaire survey. A set of data was examined by being compared to reveal the state of older people's well-being criteria predominance in the various sample groups.
\end{abstract}

(C) 2016 Published by Future Academy www.FutureAcademy.org.uk

Keywords: Mentoring, well-being, older people.

\section{Introduction}

Mentoring is not a new concept; in fact, mentoring existed in Russia during the Soviet era. Today, it is widespread in Western countries. The present study examines the revival of mentoring, viewed as a career developmental relationship between an experienced worker and a less experienced worker (a young professional); in particular, a mentor is an experienced senior worker reaching the retirement age. Creating a mentor program in organizations and enterprises is a way of enhancing social status and financial well-being of older people performing as integral members of society. The multiple benefits of implementing a mentoring program involving pre-retirement and senior workers are the following: reducing the cost of training, loss prevention due to the lack of experience of young professionals, promoting the creation of a "culture of production." The present study draws primarily on a survey 
eISSN: 2357-1330

Selection \& Peer-review under responsibility of the Conference Organization Committee

conducted among people of retirement age and research on the conceptual apparatus of the welfare state in an attempt to determine the factors influencing the social status and financial well-being of older people.

\section{The criteria of the state of older people's well-being}

According to the United Nations, the "older population" refers to those aged 65 and over. In Russia, at the beginning of 2014 the senior population was almost $13 \%$. According to Rosstat, the average life expectancy in Russia is 71 year, 76.5 years for females and 65.5 years for males by (wikipedia) in the text. The constant increase in the proportion of the senior population is one of the major problems inherited from the XXI century of the past century.

International non-governmental organization HelpAge International using statistical data from national institutions and international organizations, explores quality of life index (Global AgeWath Index) - and the well-being of the elderly. Representatives of HelpAge International, indicate that in the XXI century there are global demographic changes related to the increase in life expectancy around the world, and the aging of the population occupies a central place in them, because by 2050 the elderly (aged 60 years or older) will account for more than one-fifth of the total world population (22\%), while their number was 2.03 billion compared to the current 809 million (11\%). However, up until now there is no an international standard that would demonstrate some favorable conditions for life for the older people in various countries because global comparable data is still limited. There is a particular lack of data on older persons. Moreover, constant delist of senior people from the national and international agenda is one of the biggest obstacles to meet the needs of older people throughout the world. According to the authors of the project, the research may help attract attention to the role of older people in the social, economic, cultural and spiritual life of society. The aim of the study is to reveal the multidimensional nature of the quality of life and wellbeing of older people, and to provide a means by which to measure performance and promote improvements.

HelpAge International's Global AgeWatch Index ranks countries by how well their ageing populations are faring. The index provides a measure of 13 different indicators across four key domains of income security, health status, education and employment, as well as aspects of the enabling environment already identified by older people as being of utmost importance to them.

1. The income security domain assesses people's access to a sufficient amount of income, and the capacity to use it independently, in order to meet basic needs in older age.). It includes coverage of retirement income, the level of poverty of older people, relative welfare indicator of the elderly per capita GDP.

2. Health status (onset of old age is associated with physical weakness and the risk of bad health and disability). It includes health problems, life expectancy, and psychological wellbeing of people over 60 .

3. Capability domain includes employment rate, education level and duration of active life of the population aged 60 and over. The employment and education indicators in this domain look at different aspects of the empowerment of older people.

4. Enabling environment (older people want to have freedom of choice to lead independent and autonomous life). This domain uses data from Gallup World View to assess older people's perception 
http://dx.doi.org/10.15405/epsbs.2016.02.10

eISSN: 2357-1330 / Corresponding Author: Varlacheva Natalia, Email: valecheva@bk.com

Selection and peer-review under responsibility of the Organizing Committee of the conference

of social connectedness, safety, civic freedom and access to public transport - issues older people have singled out as particularly important.

Both older people and politicians claim that these domains perform the target components of the well-being of the older population. Countries are ranked from 1 to 96 , with 1 being the highest rank. The higher the rank, the better the quality of life for older people. The total index is calculated as the geometric mean of the four regions and shows the way, how close a country is to the ideal value. For example, the total value of 35.0 index points means that the well-being of older people in a country is only $35.0 \%$ of the ideal (100). For instance, Norway ranks first on the Global AgeWatch Index. As with many other countries in its region, Norway ranks consistently high across all domains, including first for income security with the highest GDP per capita in its region, Switzerland - third, Russia sixty-fifth by (Humanitarian encyclopedia) in the text.

Let us give a definition of the word "well-being". According to the explanatory dictionary by Dahl, well-being means "relaxed and happy, without any disturbances for cases of life or satisfaction, material security" by (V.I. Dal. (1863-1866)) in the text. "Personal well-being or happiness is determined by the material side measure of desire and the ability to meet them," by (D. I. Mendeleev. (1995)). In Macmillan dictionary "well-being" is defined as "the satisfactory state that someone or something should be in, that involves such things as being happy, healthy, and safe, and having enough money". We are inclined to view the concept "well-being" as a subjective one having various criteria for defining, but being characterized by a certain state of mind, reliability, security, does not influence the unexpected negative effects. Based on this definition following criteria have been identified. The criteria characterize the of well-being: psychological, emotional, financial, psychological and social.

Each criterion includes several features:

psychological:

- $\quad$ positive and negative emotions;

- restlessness;

- the external environment;

- $\quad$ security (confidence in the future).

emotional:

- communication with relatives, being an integral part of their lives;

- the presence of your favourite things, the ability to deal with them;

- the possibility of obtaining various information flows;

- free time.

financial:

- compliance with the financial capacity needs of the individual;

- confidence in the financial stability;

- the lack of lack of funds.

physiological:

- $\quad$ satisfactory health;

- the ability to solve the problem independently.

social: 
- $\quad$ successful functioning in society;

- $\quad$ social stability;

- $\quad$ social security.

From our point of view, factors that characterize of well-being criteria are interrelated and derived from one another.

For example, the factors affecting the financial well-being criteria determine the possibility of a positive realization of the psychological, emotional and physiological state of well-being criteria: deviations from the standard health indicators are aligned with the reference to the financial impact of access to information flows are often associated with financial security. The ability to communicate with loved ones in the remote mode is also available, with financial support, etc. To put it briefly, financial the state of well-being is achieved through the influence of social criteria: the success of the individual in society and social security, government support.

\section{Mentoring in organizations as a factor affecting social status and financial well-being of older people.}

On the basis of the above-mentioned set of criteria for older people's welfare we advance a hypothesis that the state of well-being is achieved by the older people in terms of financial satisfaction, social employment, good physical health and emotional stability. We assume that the combination of these criteria can be realized through the employment of older people in the workplace in the main, permanent jobs on part-time work as a consultant, expert, inspector quality of work, mentor young professionals. The approach seems to be appropriate to older people in achieving the well-being on all five criteria, and the company improve the quality of young specialists, to prevent the "loss" accumulated during the long work experience. The main restrictions on the implementation of a mentoring methodology through the involvement of elderly people that came from the factory to a pension - highly qualified teacher, the need for enterprises to young professionals, requiring adaptation of the workplace, having the ability and desire to work for the elderly. To confirm the hypothesis we have identified a group of 30 older people who are retired, who worked on the last place of work for more than 20 years, classified into three groups:

- $\quad$ older people who retired and keep in touch with the last place of work, do not work

- older people who retired and continue working at the company as consultants, supervisors, experts, mentors

- older people who retired and work in another enterprise and lost the touch with the previous organisation

To reduce the dependence of the research data from external and internal factors of a different nature, a restriction "other things being equal", implying that other factors affecting the well-being, in addition to the test we have at this stage not taken into account. Each group consists of 10 people. The respondents are male and female, aged 60 to 90 years. Region of study is Russia, Tomsk. All respondents are qualified, experienced professionals, with satisfactory indications of emotional wellbeing, who have worked at the same place for over 20 years and retired, various industrial branches.

The questionnaire consists of the following questions: 
1. Gender $(\mathrm{M} \backslash \mathrm{F})$

2. What is your education (9 grades of basic general, average (full) general (11 classes), initial professional (school); secondary vocational (College) higher professional)?

3. Date of birth

4. Do you work after retirement? If you do, name you current working place:

- it is a company you worked for before retirement;

- it is another company.

5. What is your occupation (consultant, mentor, another variant)?

6. Select the most appropriate the definition of "well-being" of the proposed below:

well-being - is relaxed and happy, without any disturbance over cases of life or satisfaction, material security;

personal well-being or happiness is determined by the material side measure of desire and the ability to satisfy them;

well-being - a subjective concept that has different criteria for defining, but characterized by a certain state of mind, reliability, security, does not violate the unexpected negative effects.

7. Which of the well-being criteria are relevant to your life; arrange them in descending order: financial, emotional, physiological, psychological, social, all equally realized.

8. Choose criteria that influence well-being of older people.

9. Choose the most important criteria of well-being for the older people.

Comparing the results of the study it can be concluded that $70 \%$ of elderly, retired employees who support mentoring system determine that their lives are implemented all the proposed criteria of wellbeing. It is claimed that the most important is the financial criterion ( $80 \%$ of this group respondents).

$60 \%$ of retired respondents consider that they lack the financial and physiological criteria of wellbeing; $50 \%$ of respondents pinpoint the high proportion of the implementation of social and emotional criteria, $90 \%$ define financial criteria as the most important.

Older people who retired, work in another enterprise and lost the touch with the previous organization emphasize the great role of ace of work release in the first place, as realized in their lives, financial, physiological criteria for $70 \%$ of respondents. $50 \%$ of respondents indicate the presence of a low proportion of mental and social criteria. $30 \%$ of respondents say the psychological well-being as a criterion for a little present in their lives. At the same time, $90 \%$ of respondents in this group financial criterion of well-being is defined as the most important.

To recapitulate the findings of the present study: to improve the state of well-being retiring employees may work as mentors in the company they retired from.

\section{References}

World Population Ageing: 1950-2050[electronic resource] http://www.un.org/esa/population/publications/worldageing19502050/

V.I. Dal (2011) Dictionary of the Russian. (1st volume) Moscow Society of Lovers of Russian Literature, established at the Imperial University of Moscow.

D.I. Mendeleev (1995) Cherished Thoughts: Complete Edition (the first time since 1905). Moscow: Thought. 